\title{
Concrete Characterization through digital image processing techniques
}

\author{
Positieri María, Fornari Javier, Baronetto Carlos, Oshiro Angel, Begliardo Hugo
}

\begin{abstract}
- the concrete quality evaluation is defined by the statistical processing of the resistance values obtained from the rupture test specimen (potential strength), or samples (real strength). In certain occasions, when the methods above mentioned are not possible or in order to get extra information, mainly on-site, it is common to use nondestructive testing (NDT). Lately, taking advantage of photography cameras and the growing capacity and processing speed of computers, strength evaluation and concrete deformation measuring procedures have been developed based on no-contact techniques consisting of images record, their subsequent digital processing and their treatment through algorithms of computing engineering. This paper $s$ suggests developing, based on new techniques, a classification model of conventional concrete based exclusively on the shooting of images and the subsequent proceeding of the characteristics deduced from their digitalization. The images come from tests and/or witnesses to be tested in the tutor College, National Technology University, Córdoba Regional College, while their proceeding and the extraction of correlations with the obtained strength in those tests, was done in the tutored College of the National Technology University Regional College Rafaela
\end{abstract}

Keywords - Concrete, digital proceeding, images, quality

\section{Introduction}

Concrete is a building material, made from the combination of aggregates, portland cement, water and some additives, as long as it's necessary. Although concrete was invented many years ago, its use in civil engineering applications continues to broaden. The main factors for this to occur are, in first place, the fact that it's an inexpensive material and easy to produce, and, in second place, it hasn't been found any other material that replaces its strength characteristics. The strength signals the measure of the necessary stress for a material to break. One of the most common tests in concrete is the compression test. One of the reasons of the concrete resistance compression frequent use is that the characteristics of the concrete are directly related to the compressive strength.

The usual and most accurate way to evaluate the quality of concrete is to carry out physical assays on test tubes (potential strength finding), or on samples taken from the construction sites (real strength determination).

Positieri María / Baronetto Carlos / Oshiro Angel

Argentine Technology University Regional College of Córdoba, CINTEMAC Argentina

Fornari Javier / Begliardo Hugo

Argentine Technology University Regional College of Rafaela, Civil

Engineering Department
Argentina

In both cases the tests are destructive, producing lab residue that, if it's not recycled (for example, as aggregates in new concrete), it must be disposed.

The determination of the compressive strength through destructive test methods produces a cross sectional reduction in the structural members and, consequently, a decrease of the loading capacity. In addition, these techniques use up much time and are expensive. Instead of this, low-cost and economic solutions are needed to test the compressive strength of concrete. The non-destructive techniques, such as the ultrasonic velocity, penetration of shank and pull-off, give estimated results about the compressive strength through empirical formulas based on a series of tests previously carried out in a lab. The non-destructive test methods are the following: rebound hammer, ultrasonic speed and measurement of resonance frequency, pull out tests, penetration tests, radioactive and magnetic methods. [1] [2] [3] [4].

Lately, methods for the testing of compressive strength and measurement of concrete deformation based on non-contact techniques have been developed, mainly through vision systems or the shooting of pictures and their following processing, favored by the ongoing improvement in photography and computers ability [5]. These techniques, which imply and improvement in respect to the traditional use of sensors such as strain gages, are not affected by variation due to weather conditions, something which happens with the last-mentioned ones; they also avoid residue generation and the final cost associated with disposing, among other aspects.

Currently, there are records of stress and displacement in concrete based on digital images processing among them, some authors make use of Moiré sampling method, [6] others, opt for labeling the surface of the tube to measure [7]. In the case of [5], it is done using measuring techniques based on video sequences from a standard photography camera. In all these cases, the measurement is done placing the structure or the analyzed specimen under a specific loading state. However, few records can be found in literature related to the use of techniques based on images analysis, as an alternative means, without leaving aside conventional assays (destructive and non-destructive), to evaluate the impact of aggregates shapes on the concrete properties [8] or their quality, both in lab and on-site [9]. 
The following article is structured in this way: in the first section, there's an introduction to the structure and study of concrete; in the second part, the methodology used for the shot and analysis of images is exposed. In the third section, the results obtained due to the digital images processing are presented. And in the last part, the conclusions of the work are exposed.

\section{Methodology}

In order to carry out this work, it is proposed the shooting of images, pre-proceeding, segmentation and digital analysis of the particles to verify the quality of concrete strength the image 1 shows the stages of the suggested model.

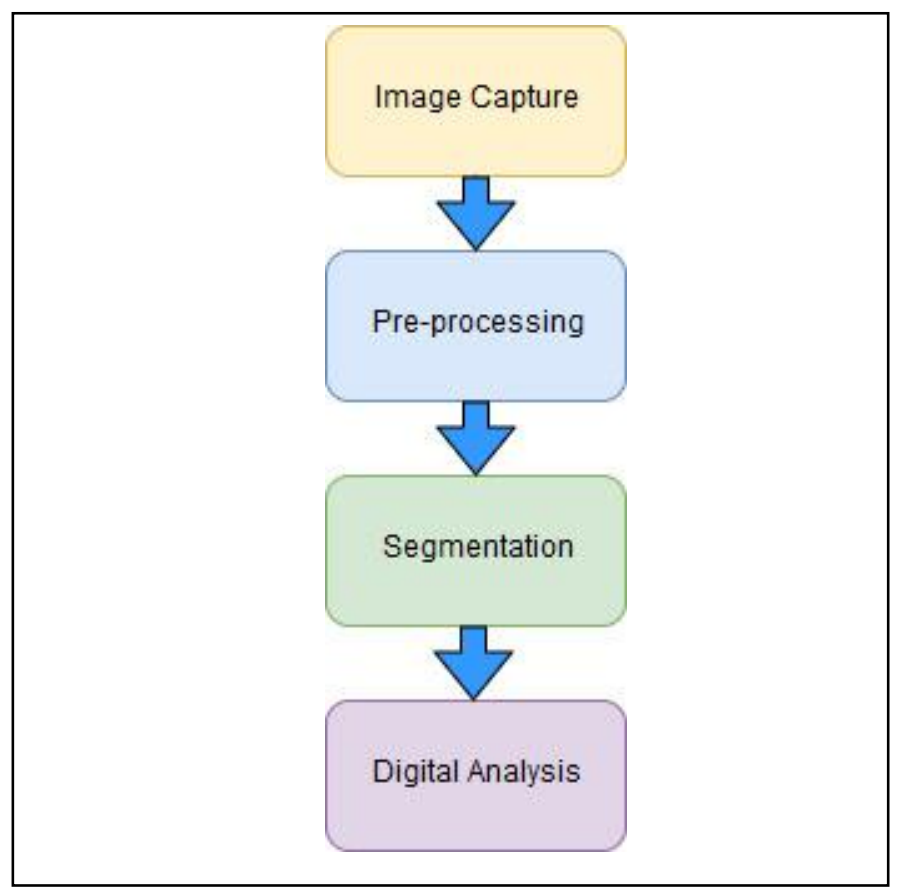

Figure 1. Stages of the model for the analysis and proof of the quality of concrete.

\section{A. Shooting of images}

The first stage is the one in charge of capturing images from different tests specimen and types of concrete. The slices of each specimen have been captured with a digital reflex camera Nikon D3300 of 24.2 megapixels of maximum resolution. The format used was RAW, in order to later on edit the photos, filter and turn them into JPG for their processing.

During the shooting process, the camera is set on a tripod, in vertical position and in a $37 \mathrm{~cm}$ height approx., in order to ensure the spotlight and zooming (Figure 2).

In the case of lightning, no special caution has been decided to consider, with the exception of the need of light to be natural in order to allow the outlined thoroughness and the darkening of the pores due to their shadow, to have a better and clearer identification. For the digital processing of the images, (DIP) the open code software ImageJ

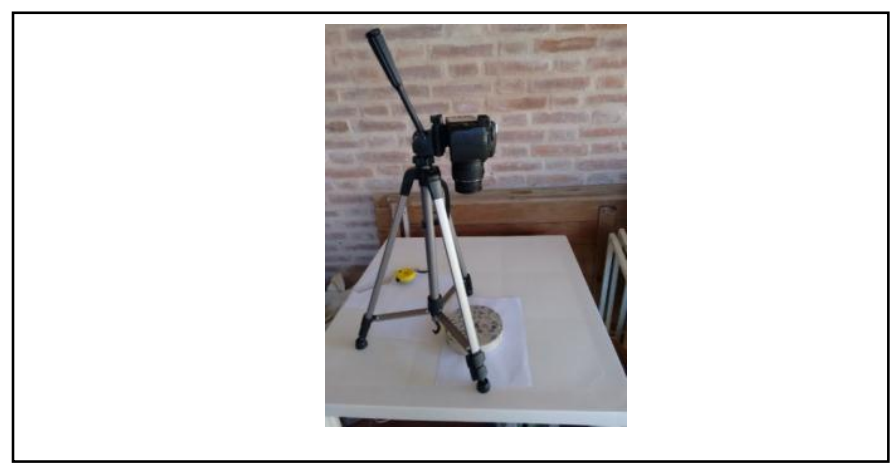

(https://imagej.net/ImageJ) has been used.

Figure 2. Camera position and distance from the object to be captured.

\section{B. Pre-processing}

In this stage, criteria for the digital separation of the coarse aggregate and the mortar pouring has been taken from the matrix (mortar), the one used to carry out grain size analysis, which considers stone or coarse aggregate everything that is held in the sieve ASTM \#4 (IRAM 4, $76 \mathrm{~mm}$ ), and the remainder as sand that's going to be part of the mortar, as it can be seen in figure 3 .

On the base of that, the program interprets and considers a stone any surface that is projected form the aggregates of equal or bigger area to $17,80(\approx 18) \mathrm{mm} 2$, equal to a circle registered in that sieve. If the particle showed an acicular shape and its surface exceeded the signaled value, it was considered as such; if it was smaller, it went over the sieve and was not calculated by the software.

In this case, the circularity of the stones was not considered, in order to allow that no matter the shape, all of them were going to be included in the selection. Circularity is computer evaluated by the formula 1 :

$$
C=\frac{4 \pi A}{p^{2}}
$$

in which $\mathrm{A}=$ projected particle area and $\mathrm{P}=$ perimeter of the particle.
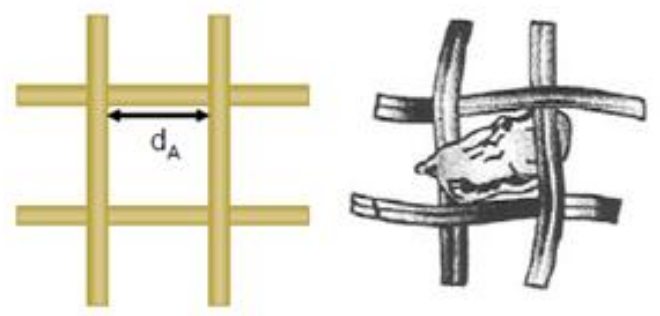
Proc. of the Sixth Intl. Conf. Advances in Civil, Structural and Mechanical Engineering - CSM 2018

Copyright (C) Institute of Research Engineers and Doctors, USA. All rights reserved.

ISBN: 978-1-63248-150-4 doi: 10.15224/978-1-63248-150-4-32

Figure 3. Sieve separator diameter, $\mathrm{d}=4,76 \mathrm{~mm}$

This way of testing circularity is known as being of high sensitivity, because it is able to count minimum changes in relation to the area. The values of $\mathrm{C}$ remain between 0 and 1 and can be seen in figure 4 .

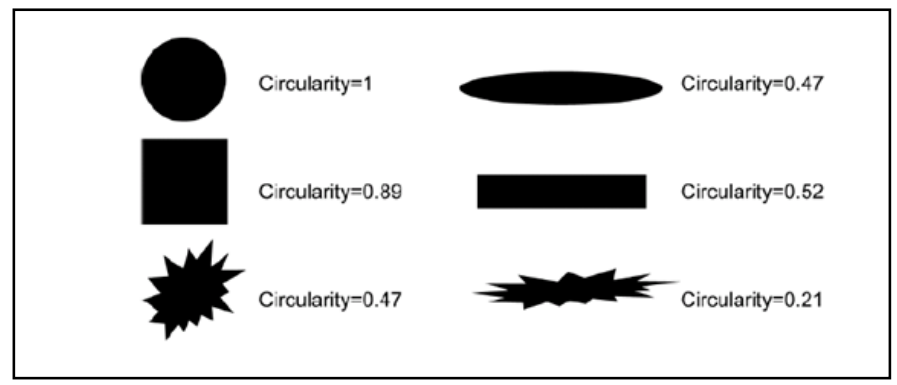

Figure 4. Circularity of different particles (Source: www.malvern.com)

The only imposed limit was in relation to its current size, since it was not supposed to be smaller than $17,80(\approx 18)$ $\mathrm{mm} 2$. Figure 5 shows the circularity and size selection used in the software as the coarse aggregate was selected.

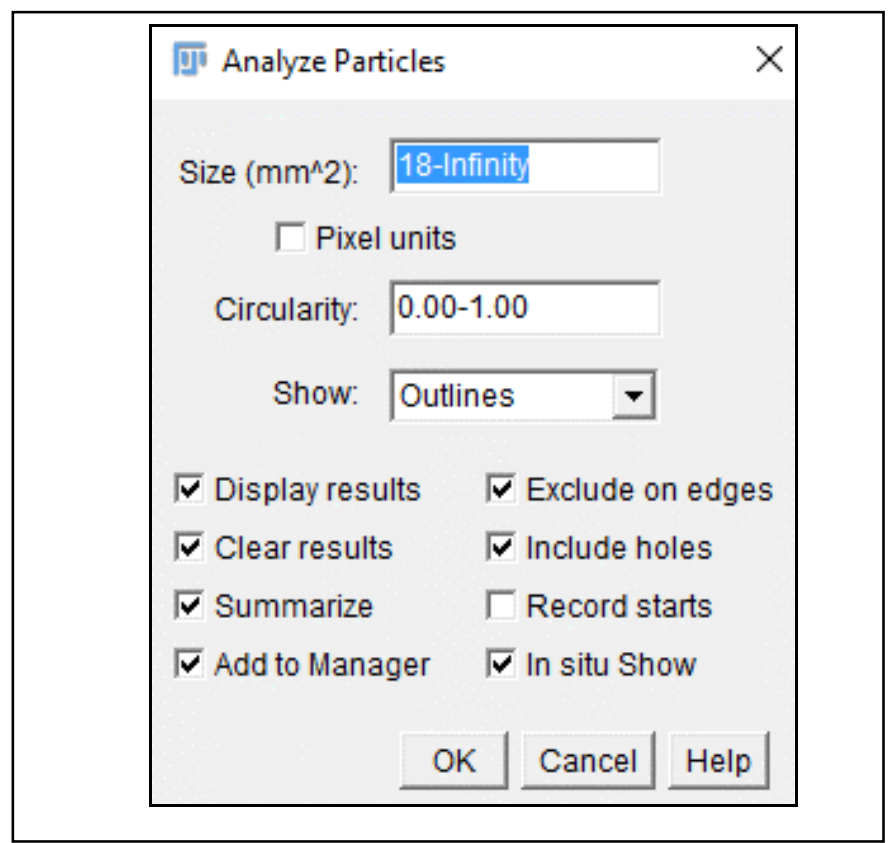

Figure 5. Selection of the range of sizes and circularity of the coarse aggregate

Another point to consider was the voids generated in the surface, also defined as porosity. This is a decisive factor in concrete strength, reason why it was considered an important element used for segmentation, using it as a parameter, similar to what was done with the stone. The influence of porosity in concrete and mortar strength is distinguished and addressed by many authors. [10] [11] [12] [13] [14] [15] [16]. In that aspect, [17] and [18], have also kept in mind this air void separation when testing concrete strength through images processing. It is assumed that only the porosity that forms part of the mortar is taken into account, leaving aside the one from the coarse aggregate.

Concrete porosity can be broaden to a vast measures rank, from the Nano scale to millimetric. Four types of pores are identified, as it is illustrated in Figure 6. At a Nano scale level, porosity appears between the layers C-S-H; from Nano scale to micro scale capillary networks can be observed due to the excess of free water in the concrete, identifying them as gel pores $(0,5 \mathrm{~nm}$ to $10 \mathrm{~nm})$ and capillary pores $(10 \mathrm{~nm}$ to 10 $\mu \mathrm{m}$ ); between $50 \mu \mathrm{m}$ and $1 \mathrm{~mm}$ porosity is a result, mainly, if the air enters during the mixing process; finally, the millimetric scale includes those air holes caught during the concrete vibration process, having a tight relation with its

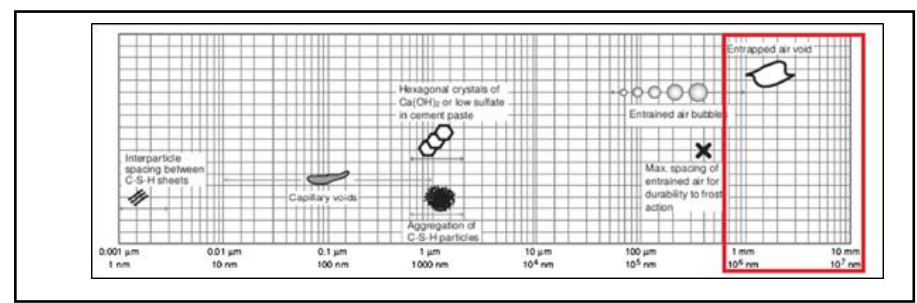

workability. [16]. in our case, this last rank is due to the process of rodding during the filling of the test tube.

Figure 6. Solids and pores concrete scale (Source: adapted from [16])

Considering what has been previously mentioned, for the digital images processing, the ideal thing would be to work with a Scanning Electron Microscope (SEM) in order to get to the smallest scales, but due to the limits imposed by the reflex camera as the one used. The work was carried out within the millimetric scale, signaled with a red box in figure 6 .

A similar criterion was used [17]. When the thresholds were set up, it was considered as the lower limit of vacuum those pores of surface of area not smaller than a $0,79 \mathrm{~mm} 2$ (related to the circle of diameter $1 \mathrm{~mm}$ ), and as an upper threshold and unlimited area surface (Infinity); while circularity was considered within the range $0,40-1,00$ as it is shown in figure 7. The tested vacuum doesn't distinguish between open and closed porosity.

\section{Segmentation}

The segmentation process of coarse aggregates and voids has been carried out separately because the steps taken, though common for both, have been in first place selection and cutting of the image; in second place the establishment of the scale in which a nominal diameter value of $15 \mathrm{~mm}$ for all the slices has been accepted; in the third place the change to gray scale in 8 bits, as it can be appreciated in figures 8 and 9; and in the last place the process of binary transformation of the image and the corresponding re touch, as can be seen in figure 10 , where the mortar slice can be appreciated with the binary conversion pre-proceeding and filling in holes already finished.

Due to the tough pre-proceeding and necessary retouching that had to be put on each image, it is assumed that both faces 
of the tube have the same layout, having analyzed only one of its sides.

Because the used stones have different tones, when it was turned into the gray scale, some hues have been confused with the mortar ones. This fact was stated when the images were transformed into binary (conversion black/white) leaving some of their layouts vague. A similar situation happened with the pores. In the case of [17] there were no problems because the coloring of the stones has been of a uniform hue and clearly differentiated form the mold which has helped to work with histograms within the scale of grays and establish threshold selection within the values that favored segmentation, both in the case of the stones and in the case of the pores. This has not been our case, so manual retouch had to be applied in stones and pores as part of the pre-processing filling out with the refilling of holes. Figure 11 exemplifies that.

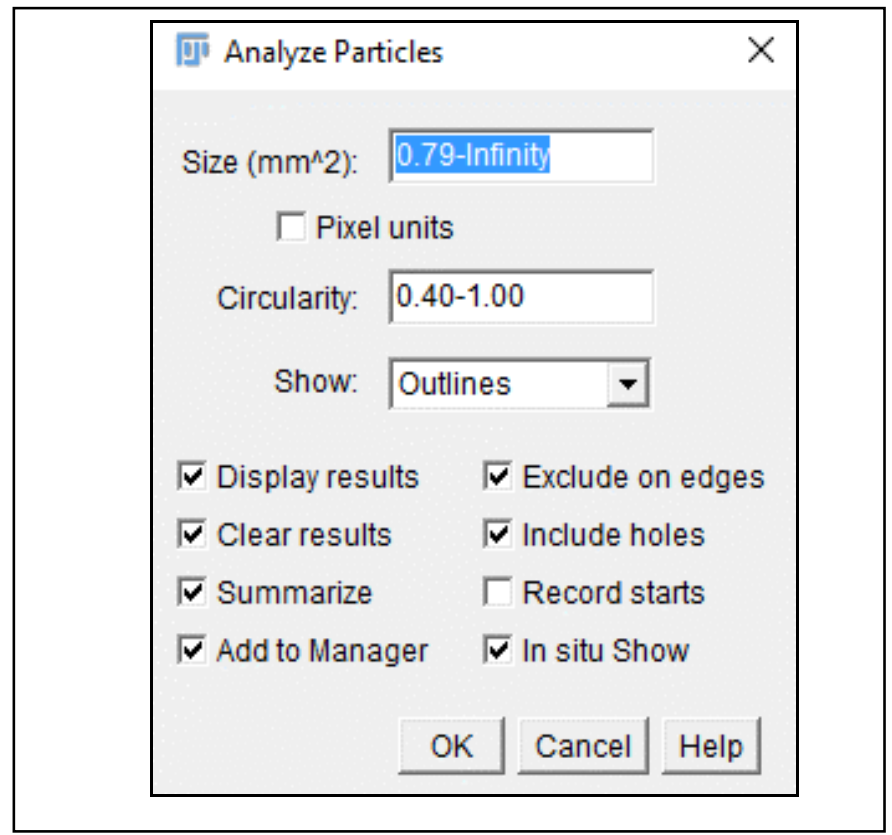

Figure 7. Selection of size ranges and vacuum circularity of concrete

However, the work done has some vagueness, especially in relation to the pores, which in a way may impact on the final calculation of their dimensions given that, as can be seen in [19] the value of the pixel hue tends to be pretty vague in the borders, as can be seen in the image with amplified pixels in Figure 12. It has been impossible to escape from that vagueness. [17].

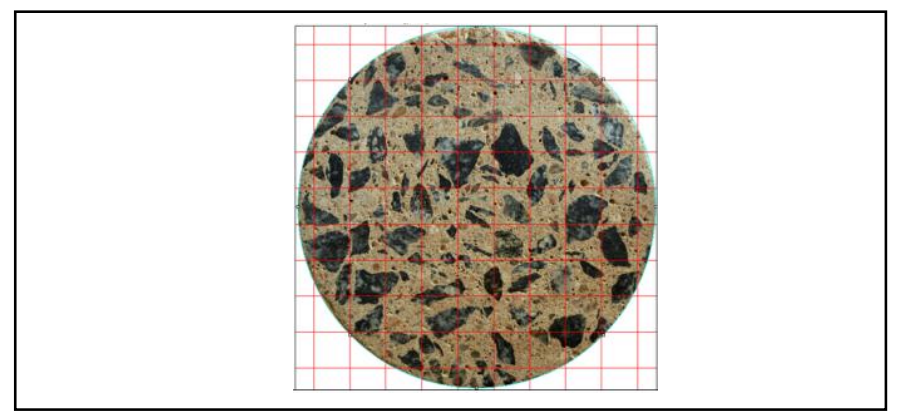

Figure 8. Original image

Figure 9. Gray scale image
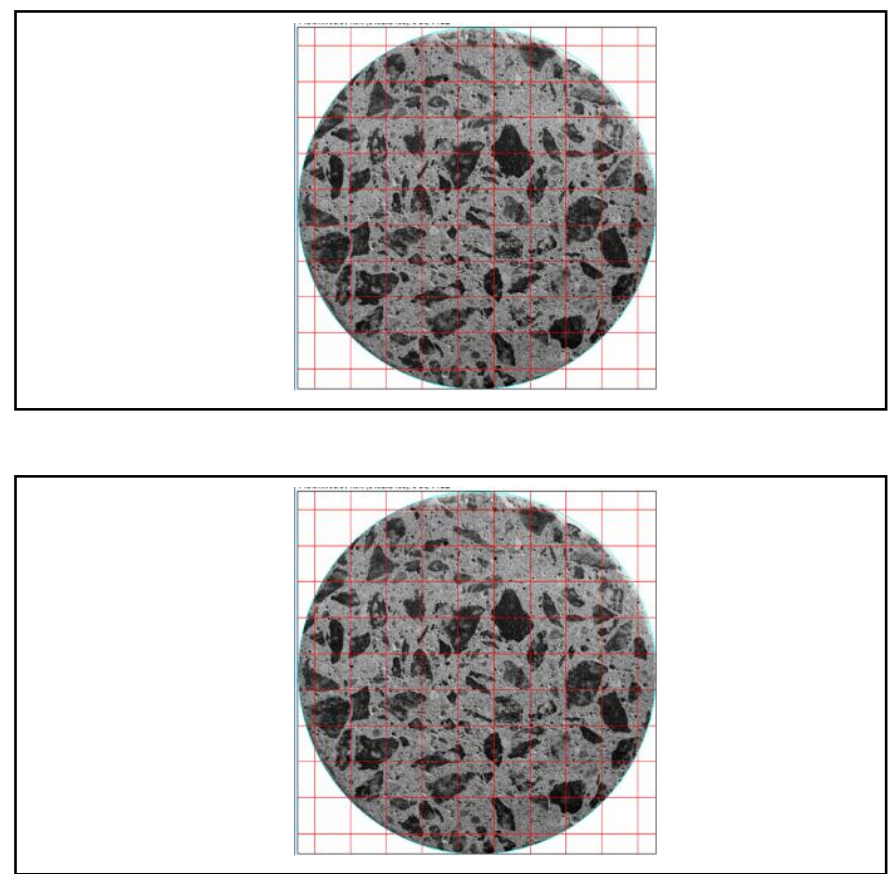

Figure 10. Final image turned into binary

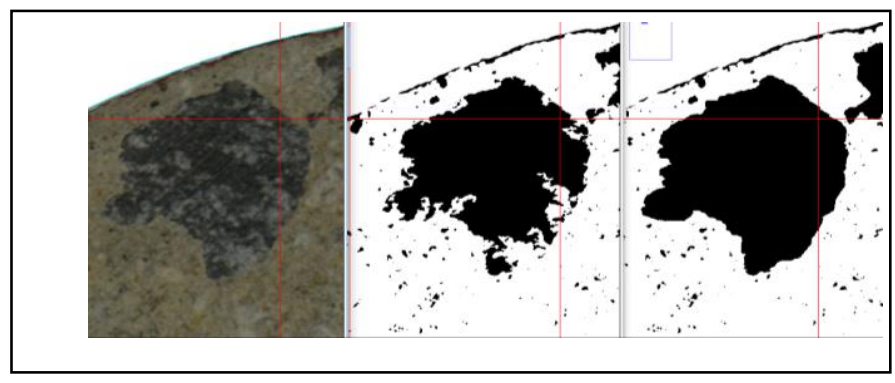

Figure 11. Pre-processing: Original image of a stone (left), turned into a binary initially (center) and transformed into binary re-touched final version (right)

\section{Digital Analysis}

In the last stage in which the digital analysis of the particles is carried out, the analysis options that appear in figures are selected 5 and 7, whether it is stones or voids, respectively. Figures 12 and 13 exemplify already segmented images of stones and pores, in comparison to pertinent to the original slice. The visible grid is a software provided resource, useful for its use in the pre-process.

\section{Results}

It has been carried out the study of segmented images of coarse aggregates and voids of one of the sides of each slice belonging to the Series T193, T204 y T213, respectively, with the location of the mass center of calculated stones and voids, 
Proc. of the Sixth Intl. Conf. Advances in Civil, Structural and Mechanical Engineering - CSM 2018 Copyright (C) Institute of Research Engineers and Doctors, USA. All rights reserved.

ISBN: 978-1-63248-150-4 doi: 10.15224/978-1-63248-150-4-32

in relation to the barycenter of each sample.

The obtained information is summarized in the following points. Figures 14 and 15 show the voids surface and the percentage in relation to the one of the nominal surface of the slices given by DPI, relating them with the determination of

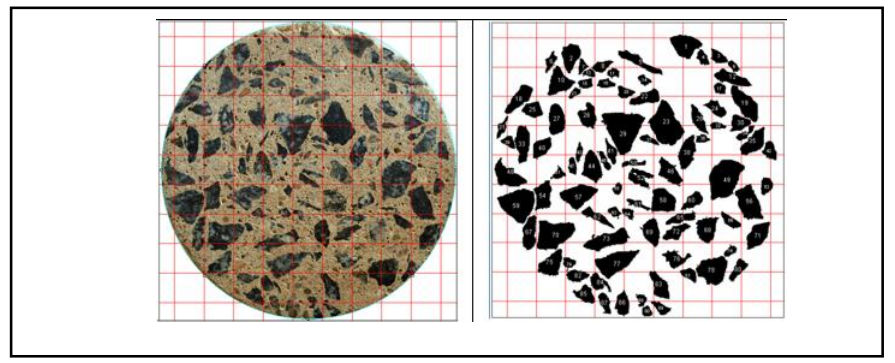

capillar suction capacity and velocity.

Figure 12. Original image (left) and segmented of the coarse aggregate (right)

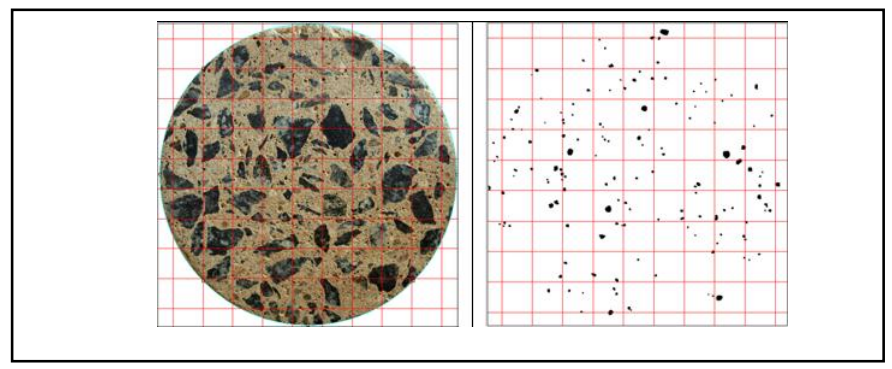

Figure 13. Original image (left) and segmented by pores (right)

A drop in the mortar content can be noticed as the relation water/cement grows. At the same time, the voids contents increases (only minimum area pores have been computed $=0$, $78 \mathrm{~mm} 2$ ). The increase given in the capillar suction capacity, just as the growing of the relation water/cement, is compatible with the percentage increase of calculated voids due to the use of the digital images processing. At the same time, that fits the determination of absorption capacity and open porosity of the analyzed sample in the Civil Engineering Lab of the National Technology University Regional College of Rafaela).

\begin{tabular}{|c|c|c|c|}
\hline \multicolumn{4}{|l|}{ Por OPI } \\
\hline \multicolumn{2}{|c|}{ Supert, probetas: } & 17671.5 & $(\mathrm{~mm} 2)$ \\
\hline \multirow[b]{2}{*}{ Roduja" } & \multicolumn{2}{|c|}{ Vacios } & \multirow{2}{*}{$\begin{array}{c}\text { Promedio } \\
\%\end{array}$} \\
\hline & $\operatorname{mm2}$ & $\%$ & \\
\hline 193 & 185,489 & 1,05 & \multirow[b]{3}{*}{1,05} \\
\hline 1938 & 168,498 & 0,95 & \\
\hline $193 \mathrm{C}$ & 200,024 & 1,13 & \\
\hline 204 & 252,329 & 0.86 & \multirow[b]{3}{*}{1,11} \\
\hline 2048 & 224,713 & 1,27 & \\
\hline $204 \mathrm{C}$ & 209,999 & 1,19 & \\
\hline $213 \mathrm{~A}$ & 206,240 & 1,17 & \multirow[b]{3}{*}{1,43} \\
\hline 2138 & 318,175 & 1,80 & \\
\hline $\begin{aligned} 213 \\
\end{aligned}$ & 234,823 & 2,33 & \\
\hline \multicolumn{3}{|c|}{ - se analiro soblo lo caro superior de c/u } & \\
\hline
\end{tabular}

Figure 14. Voids surface/nominal relation in DPI
The images of the figures 16 and 17 disclose an increase in the millimeters scale porosity, showing a bigger roughness as the relation water/cement grows (RAC).

In this case the coordinates the slices mass center: $X=75$ $\mathrm{mm}$; $\mathrm{Y}=75 \mathrm{~mm}$ (origin 0,0 in lower left side) where the absorption capacity was tested (A\%) and the open porosity $(\mathrm{Pa} \%)$ of the samples in the Lab through the saturation method of the samples for 24 hours and its following drying in oven at $105{ }^{\circ} \mathrm{C}$ until the constant weight is reached. The absorption capacity has been evaluated as can be seen in equation 2 :

$$
C A=\frac{V p a}{V t} 100
$$

Where

$\mathrm{Vpa}=$ open pores volume

$\mathrm{Vt}=$ total slice volume

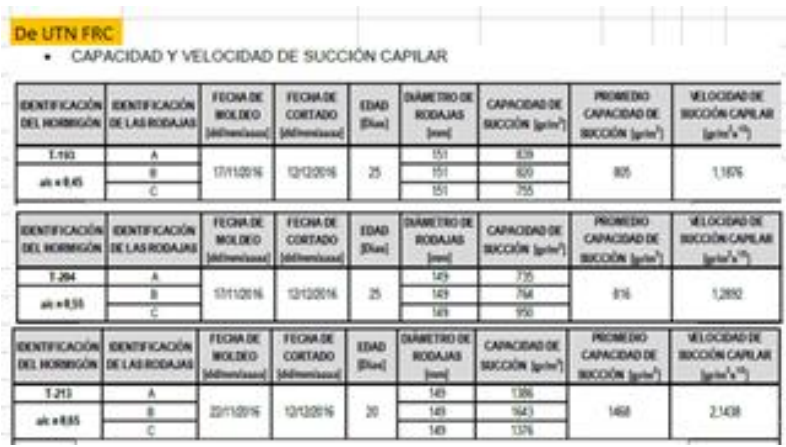

Figure 15. Capacity and speed relation of capillary suction

In the meantime, the open porosity was evaluated based on equation 3 in the following way:

$$
P A=\frac{\left(W_{s S s}-W_{s}\right)}{W_{s}}: 100
$$

Where

Wsss= saturated weight dry surface

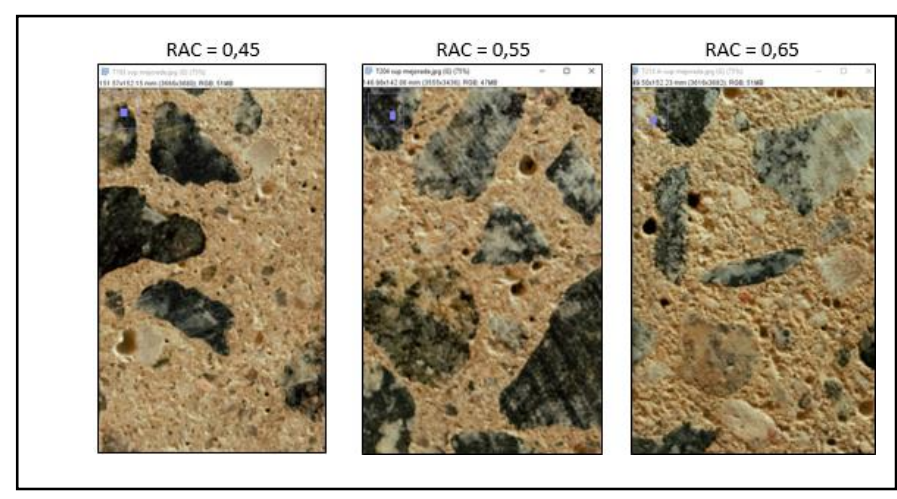

Figure 16. Porosity relation

In all the cases, one side of the sample was analyzed. Even 
though it can be assumed that the rodding calculation when the tubes are made -along with the normalized procedure- lead to a homogenous distribution of the coarse aggregate, in practice it cannot happen this way, that's why it is estimated that the analysis of the remaining side will provide supplement information and, as it allows the values average, the

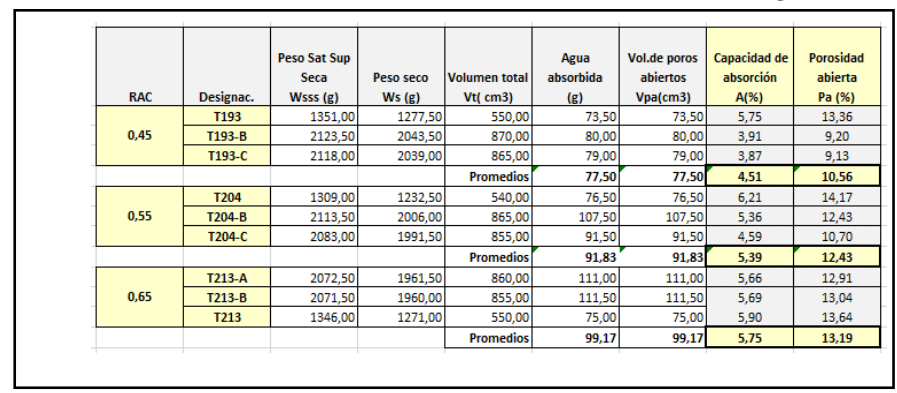

uncertainty margin about the real distribution of the inclusions (stones) and voids in the matrix (mortar) this is one of the future works to implement.

Figure 17. Numerical detail of porosity relation

\section{Conclusions}

Even though the findings of the proposed model are primary, it represents an achievement for future suggested works and an important progress in the research developed through images processing.

The obtaining of a quality classifying model of conventional concrete, will open out the studies and develop similar models for special concrete or non-conventional. Even though in our country is still limited the use of digital images processing in civil engineering field, the achieved development expects to progress in the line of a promising future.

The used software ImageJ, is a very useful tool for the digital processing of the images, and it is used in many science fields but it has been set out as line of work for the future in the research group, the automation of the detection and classification process of concrete through the use of artificial neuronal networks (RNA), in this case convolutional neuronal networks , therefore work is being done in order to broaden the information and images quantity in order to reduce the mistakes of the practice and get, in that way, suitable and applicable results.

\section{References}

[1] Hassan AMT, Jones SW. Non-destructive testing of ultra-high performance fiber reinforced concrete (UHPFRC): a feasibility study for using ultrasonic and resonant frequency testing techniques. Constr Build Mater 2012;35:361-7.

[2] Subas S, Sahin I, Çomak B. Prediction of compressive strength of concretes containing fly ash using non-destructive test results by anfis. SDU Int J Technol Sci 2010;2(3):9-16.

[3] Demirbog a R, Karakoç MB. Relationship between ultrasonic velocity and compressive strength for high-volume mineral-admixtured concrete. CemConcr Res 2004;34:2329-36.

[4] Uomoto T. Non-destructive testing in civil engineering. Tokyo: Elsevier Science Ltd.; 2000. p. 697.
[5] Ferrer B., Acevedo A., Espinosa E., Mas D. (2014). Targetless imagebased method for measuring displacements and strains on concrete surfaces with a consumer camera. Construction and Building Materials, 75, 213-219. doi: http://dx.doi.org/10.1016/j.conbuildmat.2014.11.019.

[6] Ri, S., Fujigaki, M., \& Morimoto, Y. (2010). Sampling Moiré Method for Accurate Small Deformation Distribution Measurement. Experimental Mechanics, 50(4), 501-508. doi: 10.1007/s11340-0099239-4

[7] Tanou S., Umemoto S., Miyamoti N., Takaki T., Ishii I, Aoyama T. (2013) Concrete Surface Strain Measurement Using Moiré Fringes. Available at: http://www.claisse.info/2013\%20papers/data/e428.pdf [Access: Nov 30, 2015].

[8] León R, Ramírez J., (2015), Innovative Materials and Techniques in Concrete Construction. Dordrecth: Springer Netherlands.

[9] PeláezJ., Vaccaro G., Guijarro A. (2015) Un Modelo para la Categorización de Hormigones Mediante Procesamiento Digital de Imágenes. Available

at: https://www.researchgate.net/publication/282643765_Un_Modelo_para la_Categorización_de_Hormigones_Mediante_Procesamiento_Digital_d e_Imgenes [Access: Nov 30, 2015].

[10] Popovics S., (1998). Strength and related properties of concrete: a quantitative approach.

[11] Das B. ,Kondraivendhan B., (2012. Implication of pore size distribution parameters on compressive strength, permeability and hydraulic diffusivity of concrete. Construction and Building Materials 28, 382386.

[12] Ozturk A., Baradan B., (2008). A comparison study of porosity and compressive strength mathematical models with image analysis. Computational Materials Science 43 (2008) 974-979.

[13] Śluzarek J., (2010). The correlation of structure porosity and compressive strength of hardening cement materials. Architecture Civil Engineering Environment. The Silesian University of Technology, $\mathrm{N}^{\circ} 3 / 2010$, pp. 85-92.

[14] Chen X., Wu S., Zhou J., (2013). Influence of porosity on compressive and tensile strength of cement mortar. Construction and Building Materials 40, 869-874.

[15] Zhao H., Xiao Q., Huang D. and Zhang S., (2014). Influence of Pore Structure on Compressive Strength of Cement Mortar. The Scientific World Journal. Volume 2014, Article ID 247058, 12 pages. http://dx.doi.org/10.1155/2014/247058

[16] Zingg L., Briffaut M., Baroth J., Malecot Y. (2016).Influence of cement matrix porosity on the triaxial behaviour of concrete. Cement and Concrete Research, Vol 80, pp. 52-59.

[17] Basyigit C., Çomak B., Kilinçarslan S., Serkan Üncü I., (2012). Assessment of concrete compressive strength by image processing technique. Construction and Building Materials 37,526-532.

[18] Zhou S., Shen A., Li X., and Li G., (2015). A relationship of microscopic pore structure and concrete bending strength. Material Resecar Innovaciones .Vol. 19, Supla 10.

[19] Moreira Cantu M., (2011). PhD Thesis. Pore structure in blended cement pastes. Departamento of Civil Engineering. Technical University of Denmark.

About Authors:

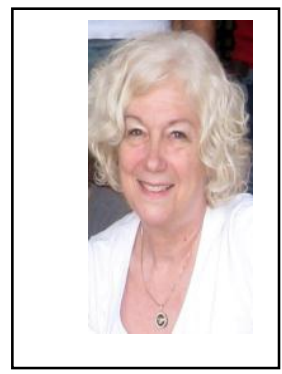

Positieri María Josefina: Civil Engineer from National University of Córdoba. $\mathrm{PhD}$ in Engineering from National Technological University, Cordoba Regional School. Director of CINTEMAC, Center for Research, Development and Transfer in Materials and Quality. Coordinator for the Cordoba Regional Faculty, National Technological University, for the implementation of the Doctorate in Engineering, Mention Materials. Coordinator at the National Technological University of the Structures and Civil Constructions Program. 


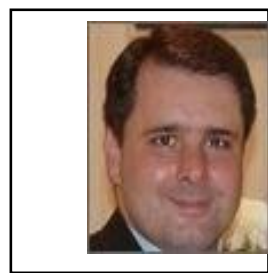

Fornari Javier: $\mathrm{PhD}$ in Computing and Systems Engineering from University of Málaga, Spain. Full Time Professor in the National Technological University in the topics related to applied technologies. Scientific research in artificial intelligence.

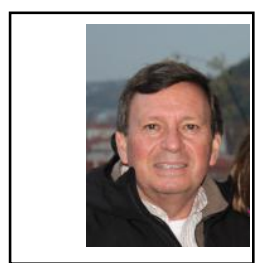

Baronetto Carlos: Civil Engineer graduated from the National University of Córdoba. Specialist in Concrete Technology and University Teaching. Full Professor in the Construction Materials Chair at the National Technological University.

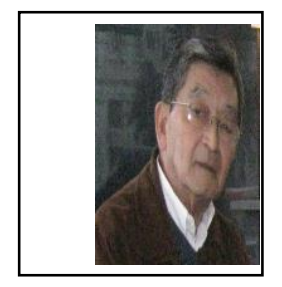

Oshiro Angel: Civil Engineer with postgraduate specialization in University Teaching and Technology of Applied Concrete. Full Professor at the National Technological University. Extensive experience in the technology of concrete.

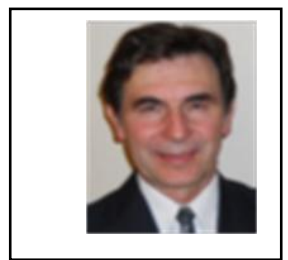

Begliardo Hugo: Construction Engineer, Civil Engineer and Master of Environmental Engineering from the National Technological University, Argentina. Full Professor of Final Project and Associate Professor of Structural Analysis. 